\title{
Depicting Dementia: Representations of Cognitive Health and IIIness in Ten Picturebooks for Children
}

\author{
Elizabeth F. Caldwell ${ }^{1}$ (D) Sarah Falcus ${ }^{2}$ D $\cdot$ Katsura Sako $^{3}$ D
}

Published online: 14 March 2020

(c) The Author(s) 2020

\begin{abstract}
It is estimated that a third of children know someone living with dementia, and there are now many picturebooks for young children that help to explain the changes dementia can bring to family life. Despite their number, there has been little examination of what these books communicate about health and illness. To address this, the current study presents a close visual and textual analysis of 10 recent picturebooks in English that aim to teach children about dementia. Our analysis reveals that in these books dementia is exclusively framed in terms of ageing, and as an illness of older adults. Furthermore, the books rely heavily on mechanistic metaphors to explain the causes of dementia. However, at the same time the "still the same person" narrative is dominant. This narrative emphasises the importance of foregrounding the unique history and personality of the person living with dementia, and offers a way to help children to continue meaningful relationships with their relatives. These books employ often ageist tropes of decline in the depiction of dementia and yet at the same time support a narrative of ongoing personhood, reflecting the complexity of broader social discourses around dementia and selfhood.
\end{abstract}

Keywords Dementia $\cdot$ Alzheimer's disease $\cdot$ Picturebooks $\cdot$ Health communication · Children's literature $\cdot$ Visual analysis

Handling EIC name: Victoria de Rijke.

Elizabeth F. Caldwell is a multidisciplinary scholar interested in social and cultural studies of science and medicine, with a particular focus on education. Her recent work has included studies of the visual culture of children's science books, as well as exploring visual aspects of health communication in picturebooks for children.

Sarah Falcus is a Reader in Contemporary Literature at the University of Huddersfield. Her research interests are in critical age studies and she is the co-author, with Katsura Sako, of the book Contemporary Narratives of Dementia: Ethics, Ageing, Politics (Routledge, 2019).

Katsura Sako is an Associate Professor of English at Keio University, Japan. She has research interests in post-war/contemporary British literature, gender and literary/cultural gerontology.

Extended author information available on the last page of the article 


\section{Introduction}

From healthy eating to understanding illness, both school and public libraries are well-stocked with books for children about health. These books aim to educate children about their own health as well as the health of those around them, and many reflect the fact that children "become involved in and, indeed, [are] proactive in health practices while growing up" (Christiansen, 2004, p. 379). As well as teaching children about keeping healthy, such books have been described as a "safe way to introduce information" to children about challenging subjects such as illness and death (Blumenreich and Siegel, 2006, p. 82). However, children's books can also reproduce particular discourses about disability and stigma (Crawford and Bhattacharya, 2014). As Tucker remarks, it is not "whether [children] should be told about such things, but exactly how" (2006, p. 208).

In this article, we consider how books - in this case picturebooks, specifically - are used to introduce young children to an illness that many are now encountering first-hand in their families and communities: dementia. This study of 10 recent picturebooks in English about dementia approaches the texts in the context of health communication to consider exactly how books about dementia for young children explain and depict the condition, and the implications of their chosen metaphors, visual and verbal. In bringing together the study of children's literature and ageing, we engage with the growing scholarship at the nexus of children's literature studies and critical age studies. Recent work in children's literature has revisited the figure of the child, and the lifestage of childhood, in ways that have implications for our understanding of adulthood and its supposed autonomy and independence (Gubar, 2013; Beauvais, 2015). More specifically, Joosen (2018) argues that we must bring together critical age studies and children's literature studies in order to rethink the relationship between the child and the older person. In considering ageing and illness in picturebooks, we seek to contribute to this developing understanding of intergenerational relationships and the lifecourse in literature for both children and adults.

The books we examine in this article often depend on a limited, and sometimes stereotypical, set of representations of illness. Both the images and the text in the picturebooks rely heavily on the association between dementia and ageing. This has the effect of creating a reassuring distance from dementia for the young child, whilst at the same time providing a simple, and common, causal explanation for a progressive condition for which there is no cure. However, by conflating ageing and illness the books may contribute to the binary between "normal" and pathological ageing and serve to delegitimise the experiences of children with parents living with earlyonset dementia. Our analysis also reveals the common use of metaphors to explain dementia in mechanistic terms that depend upon a biomedical understanding of ill health. These metaphors can contribute to the discourse of the non-person in cognitive illness, through the implication of producing a "body to be managed" (Behuniak, 2011, p. 74). Despite these depictions, which may encourage an understanding of dementia as loss of self, the books also align with contemporary dementia activism through their promotion of the message that the person living with dementia 
is still the same person. In addition, the texts engage with holistic conceptions of health, particularly in the attention paid to social roles and the affective and psychological experience of cognitive illness. The combination of words and pictures in these books offers a complex and, at times, contradictory representation of the experience of dementia that reflects the polyvocal nature of dominant and emerging discourses of dementia in society.

\section{Dementia and Picturebooks}

Dementia is a group of progressive neurological conditions that bring inevitable changes to cognition and hence to relationships within families. It is estimated that one in three children know someone with dementia and a quarter of children have a close friend or family member who lives with the condition (Noble et al., 2015; Parveen, 2015). With the increasing number of people diagnosed with dementia has come a growing recognition of the need to communicate with young children about the changes dementia can bring to family life. Despite this, parents often find it difficult to talk to their children about the condition and struggle to frame the discussion in terms that they feel children would understand (Miller-Ott, 2018).

The growing need to support children and families has led to the publication of a burgeoning number of books in the Anglophone world that expressly aim to develop children's understanding of dementia and to facilitate relationships with relatives living with the condition. These books are frequently recommended to families by advocacy organisations such as the Alzheimer's Society and Young Dementia UK, and by professional carers. Moreover, lists of recommended books and reviews of particular texts and authors regularly feature in online support communities and in the mainstream media. In the UK, local libraries, bibliotherapy groups and other reading-based organisations, such as The Book Trust and Reading Well: Books on Prescription, recommend books about dementia for children (BookTrust, 2019; Reading Well, 2020).

Alongside the increase in non-fictional texts that explain dementia to children, there has been a rapid growth in fictional narratives about dementia aimed at children and young people. There are a number of novels written for older children and young adults that feature characters with dementia, such as Downham's Unbecoming (2015) and Furniss' How Not to Disappear (2016), and others aimed at a slightly younger age group, such as Park's The Graduation of Jake Moon (2002a). For even younger children, dementia stories are told in picturebooks that are designed to educate and reassure children (and families) encountering a loved one with dementia through narratives presented in words and pictures. Alzheimer's Research UK has even produced its own children's books about dementia: Elliott and Threadgold's Grandad's Hat (2015), and Elliott and Nunn's When Grandma Came to Stay (2015). These books can be seen both as part of a broader movement to improve "dementia literacy" among communities (see for example Noble et al., 2015) and as specific resources to support communication in families coping with life-limiting illness.

Despite their growing number, there is a paucity of research on children's books about dementia. Manthorpe (2005) produced the first study in this area with her 
analysis of novels for young people about dementia. Manthorpe argued that children's literature provides a vehicle to explore "the child's eye view" of dementia, as young people negotiate the tension between the increased domestic responsibilities dementia may place on them and the desire for greater independence from the family. The first study to examine books for younger children was Sakai et al.'s (2012) content analysis of the symptoms of Alzheimer's Disease in 33 children's books, which concluded that in general the books did not give a medically accurate portrayal of Alzheimer's Disease symptoms, and did not show the progression of the disease over time. Interestingly, Sakai et al. drew their conclusions from analysing the text of the storybooks and did not consider the illustrations. More recently, Falcus and Sako's (2019) literary analysis considers both text and illustrations in a number of picturebooks featuring memory loss in English and Japanese. Their analysis of the narratives presented in the words and pictures revealed an idealisation of childhood as well as the presence of adult anxieties about dementia. Our study builds on that of Falcus and Sako, by using the lens of health communication to analyse the images and text in 10 recent picturebooks about dementia.

\section{Selecting and Analysing Picturebooks About Dementia}

In order to select our corpus, we compiled a database of 77 picturebooks about dementia, published in English. The database was assembled from a wide range of sources, including dementia and Alzheimer's Disease support organisations from the UK, USA and Australia, as well as book sellers, catalogues, academic journals and the UK national press. From the database we identified all books published after 2000 (59 books) to reflect recent developments in dementia advocacy and support. As we were interested in how health messages are imaginatively incorporated and packaged in visual and textual narratives, we excluded books with a more instructive, informative tone and strong non-fiction elements (six books). We also excluded seven books that depicted characters as animals, which would require a kind of analysis beyond the scope of this paper.

From the remaining list of 46 books, we selected every fourth book in our database until we had 10 books to make up our corpus (see Table 1). Although our final corpus included some books that were out of print at the time of the study, all titles were readily available at low prices (less than $£ 7$ ) from popular online book retailers and two were also stocked by our local public library in the UK. As such, we consider all the titles in our final corpus to be easily accessible to families wishing to find books for young children about dementia. Significantly, although all the books in our corpus feature a character with symptoms such as memory loss, not all of the picturebooks specifically use the term dementia (or related terms such as Alzheimer's Disease). Despite this, the link to dementia and the therapeutic/didactic aim are clear. As evidence of this, many of these books are recommended by dementia support organisations or their educational intentions are expressly stated in the peritexts (see Table 1).

We recognise that both our final sample and the overall database are limited in their representation of ethnic diversity, which may reflect a broader lack of diversity 


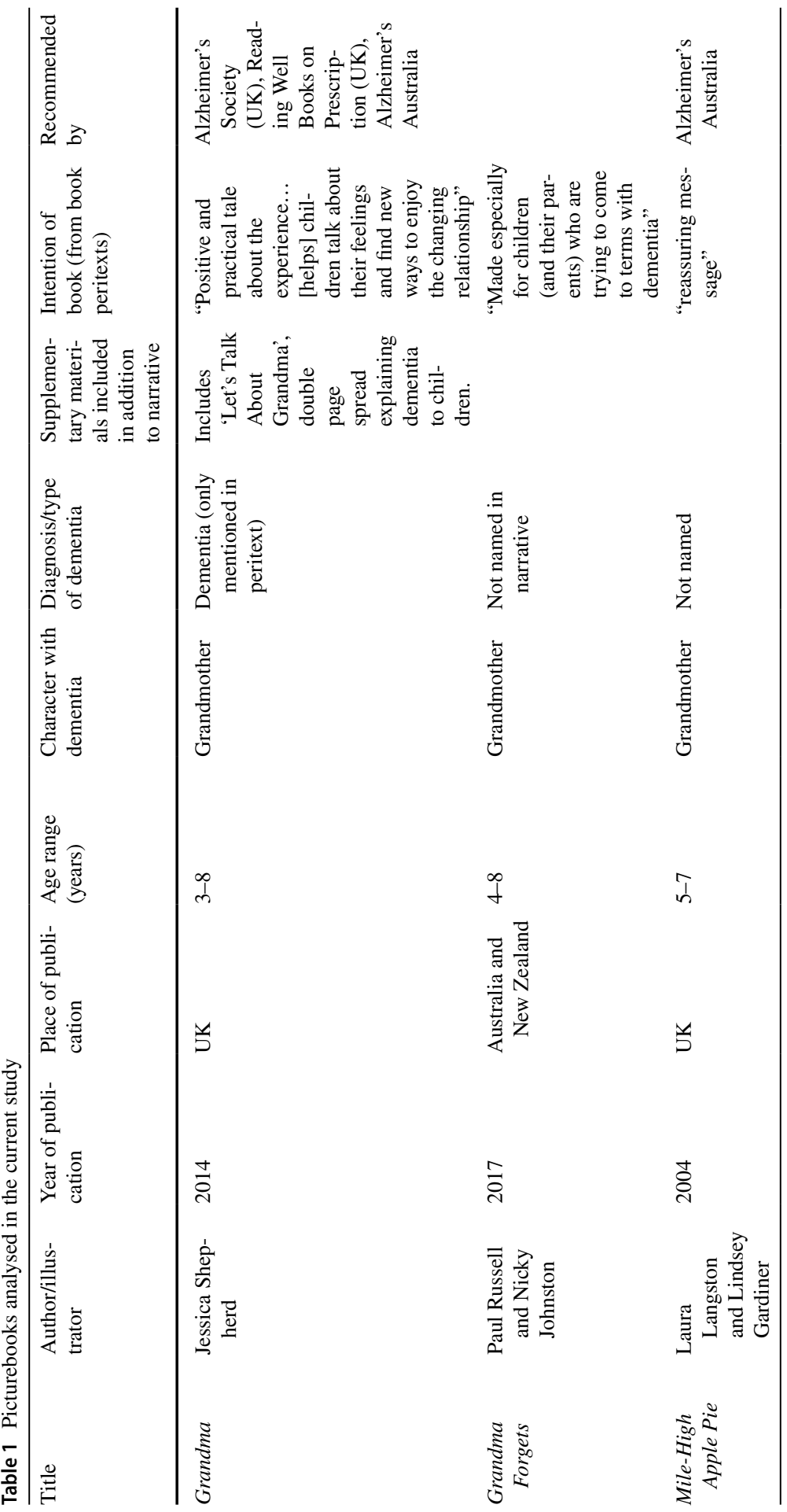




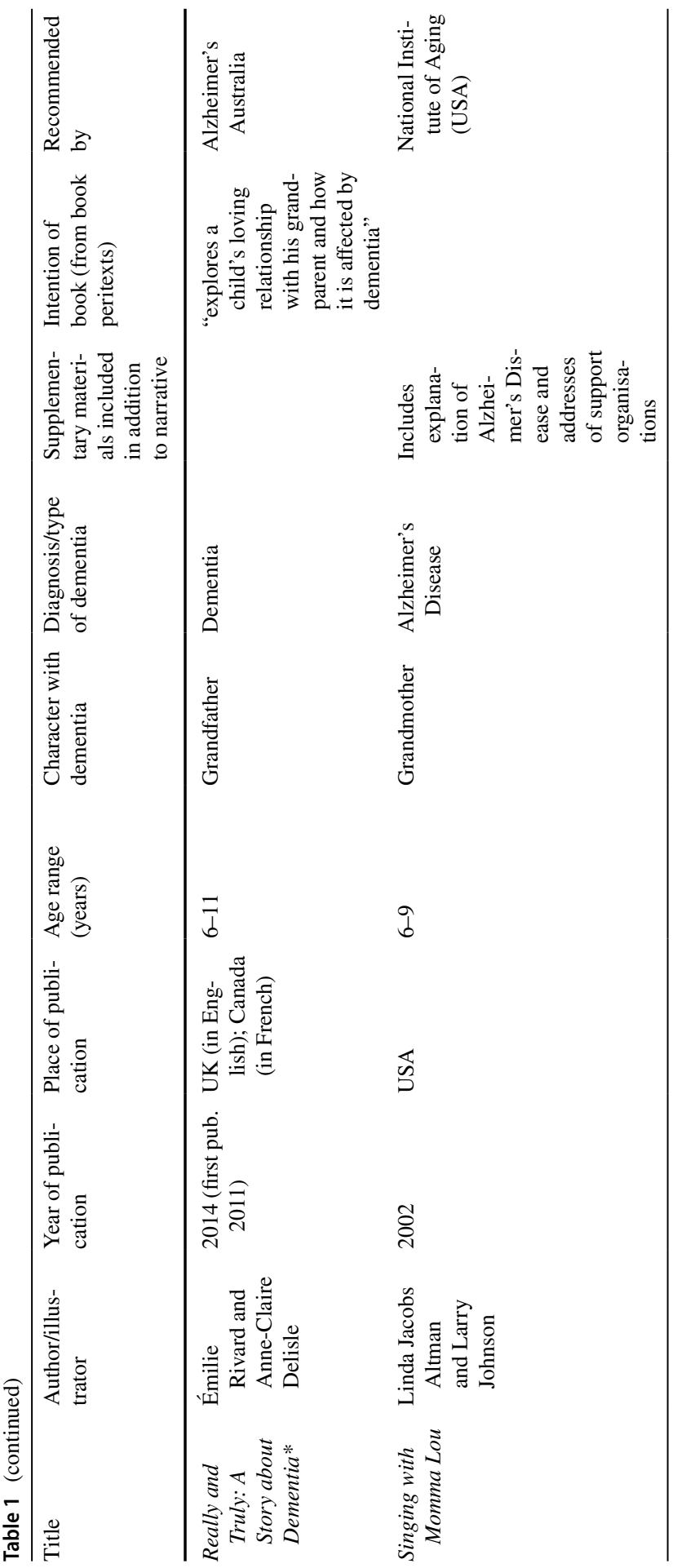




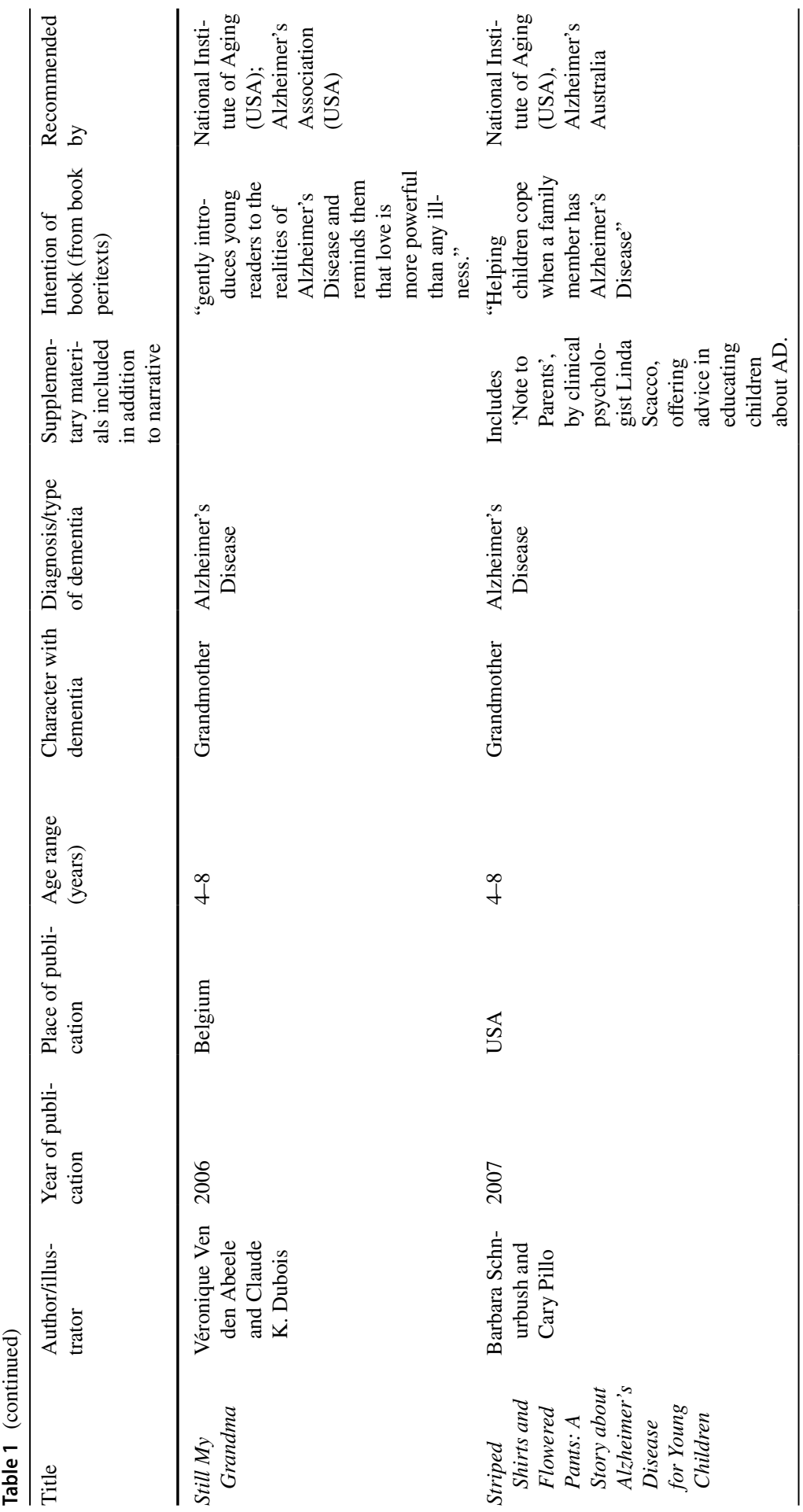




\begin{tabular}{|c|c|}
\hline 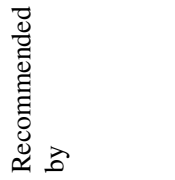 & 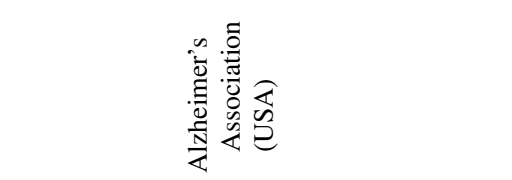 \\
\hline 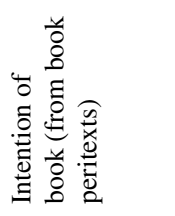 & 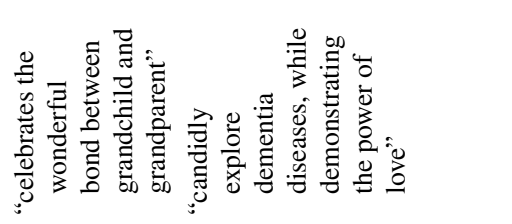 \\
\hline 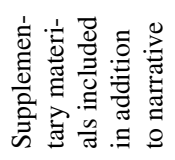 & 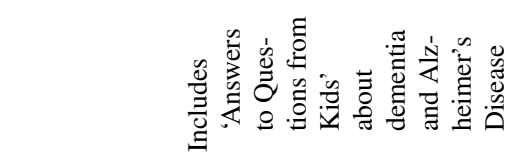 \\
\hline 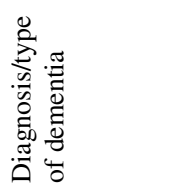 & 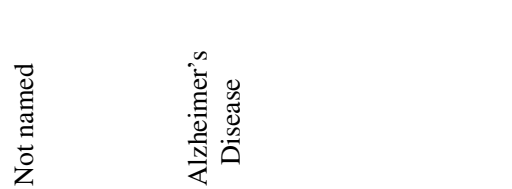 \\
\hline 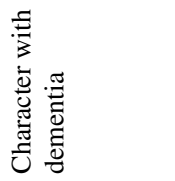 & 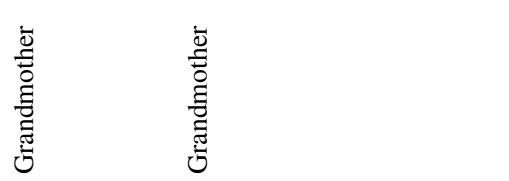 \\
\hline 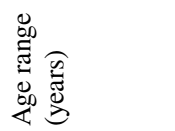 & $\begin{array}{l}\infty \\
1 \\
n\end{array}$ \\
\hline 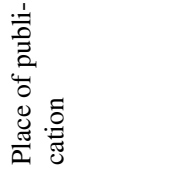 & 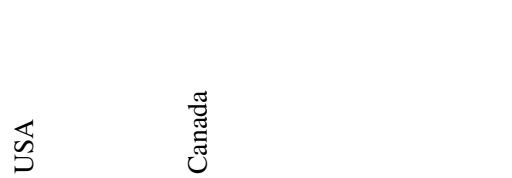 \\
\hline 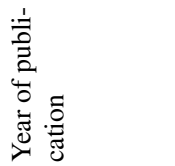 & $\stackrel{\sim}{\vec{d}}$ \\
\hline 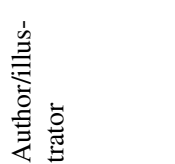 & 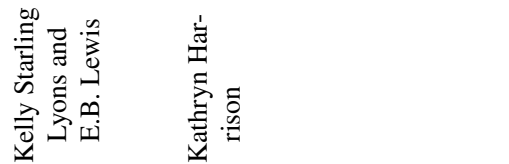 \\
\hline$\stackrel{\varrho}{\Xi}$ & 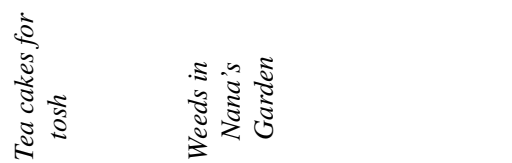 \\
\hline
\end{tabular}




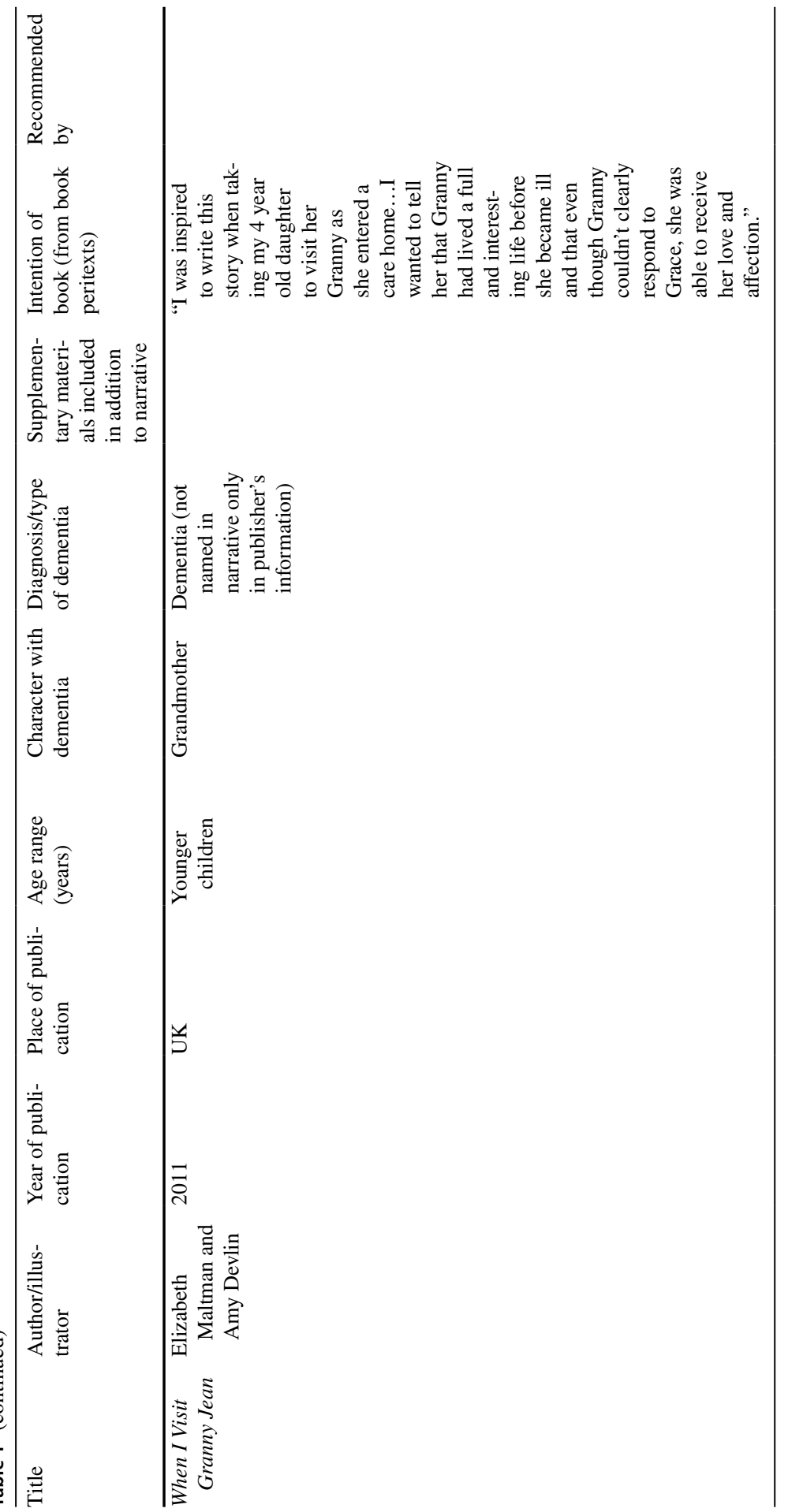

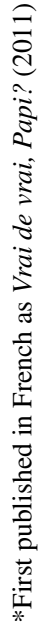


in children's literature (Centre for Literacy in Primary Education, 2018). Our final sample also includes far more books about female characters with dementia than male. This may reflect the fact that more women are diagnosed with conditions such as Alzheimer's Disease than men (Alzheimer's Association, 2017; Prince et al., 2014). Nevertheless, the relationship between dementia and sex/gender is complex. Though there are more women than men living with dementia, Mielke points out that the incidence is not always higher for women than men and that "sex and gender differences in the incidence of $\mathrm{AD}$ dementia may depend on the time period and geographical region" (2018, p. 2). It is notable that intersectional and feminist approaches to dementia are now exploring relationships between sex, gender and dementia, and the impact of these on care and public policy (Bartlett et al., 2018; Mielke, 2018; Sandberg, 2018; Rocca, 2017). Though full discussion of the significance of gender in children's books about dementia is beyond the scope of this paper, it is important to note that cultural narratives such as picturebooks do not simply reflect real-world statistics and experiences, but also help to shape the ways in which we understand dementia (including its relationship to gender).

One of the challenges for researchers working with picturebooks is giving sufficient attention to the visual aspects of the books in the analysis. As adult researchers we have to consciously attend to the pictures because, as Nikolajeva points out, "we are, from early school years, manipulated to believe that language has more weight than images" (2012, pp. 278-279). In contrast, studies of children reading picturebooks have found them to be sophisticated decoders of visual metaphor and imagery (Styles and Arizpe, 2001) and for many children, the meaning carried through pictures has more impact than that carried through the words (Sipe, 2011). As such, it is important to include images in the analysis, despite the methodological challenges that this may pose. For example, whilst content analysis is often used for analysing visual data, it does not lend itself to analysing the temporality embedded in picturebook narratives, which comprise multiple images of the same characters as the story unfolds.

In order to develop a method for analysing visual narratives in picturebooks, we adapted Caldwell and Wilbraham's (2018) methodology for qualitative visual analysis, which examines images in terms of what people are doing, wearing and touching. Our adapted method involved analysing what the characters were pictured doing, wearing and touching at key points in the narrative in order to take account of changes that occur as the story progresses (see Tables 2 and 3). In particular, special attention was paid to the appearance and activities of the characters before, and after, the child protagonist in each story recognises that their grandparent has memory difficulties (see Table 3). This initial phase of descriptive visual analysis was then combined with a multi-modal analysis of the picturebooks, to identify overarching themes in the health communication from the corpus as a whole.

In paying close attention to words and images together, we follow classic work in children's literature studies that interrogates the ways in which meaning is carried through image, text and the "synergy" between them (Sipe, 1998, p. 98). As Nodelman explains: 


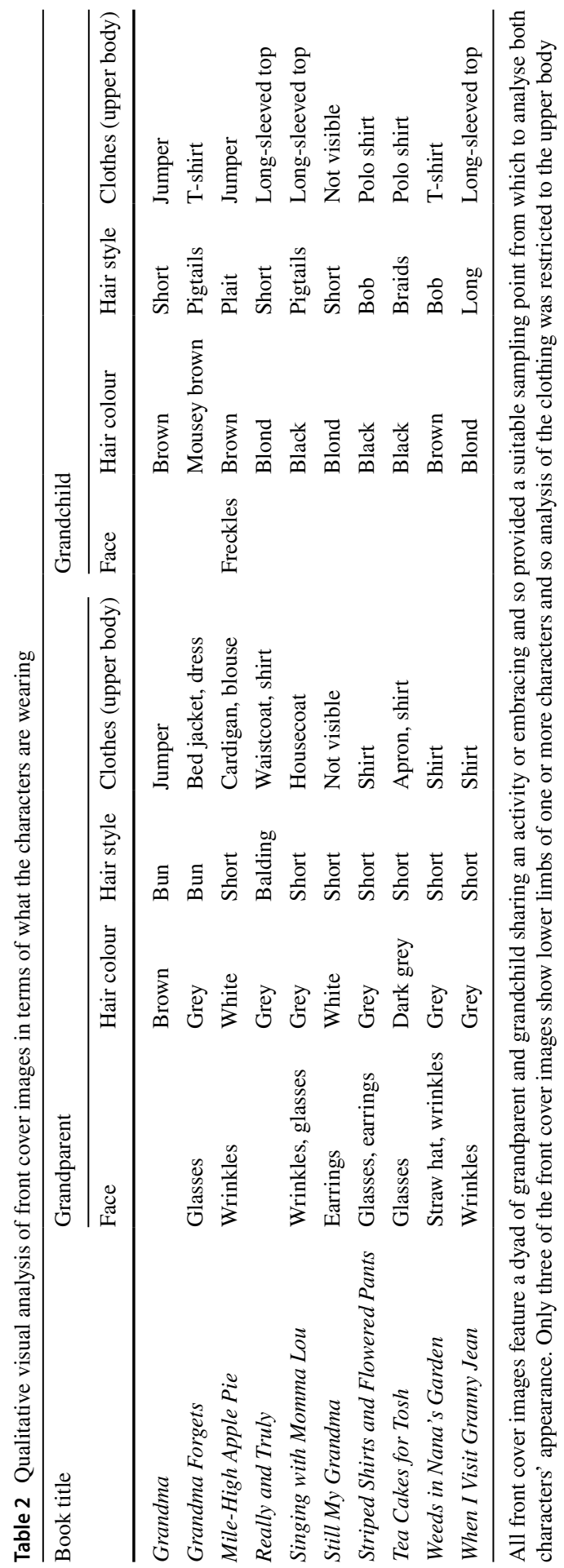




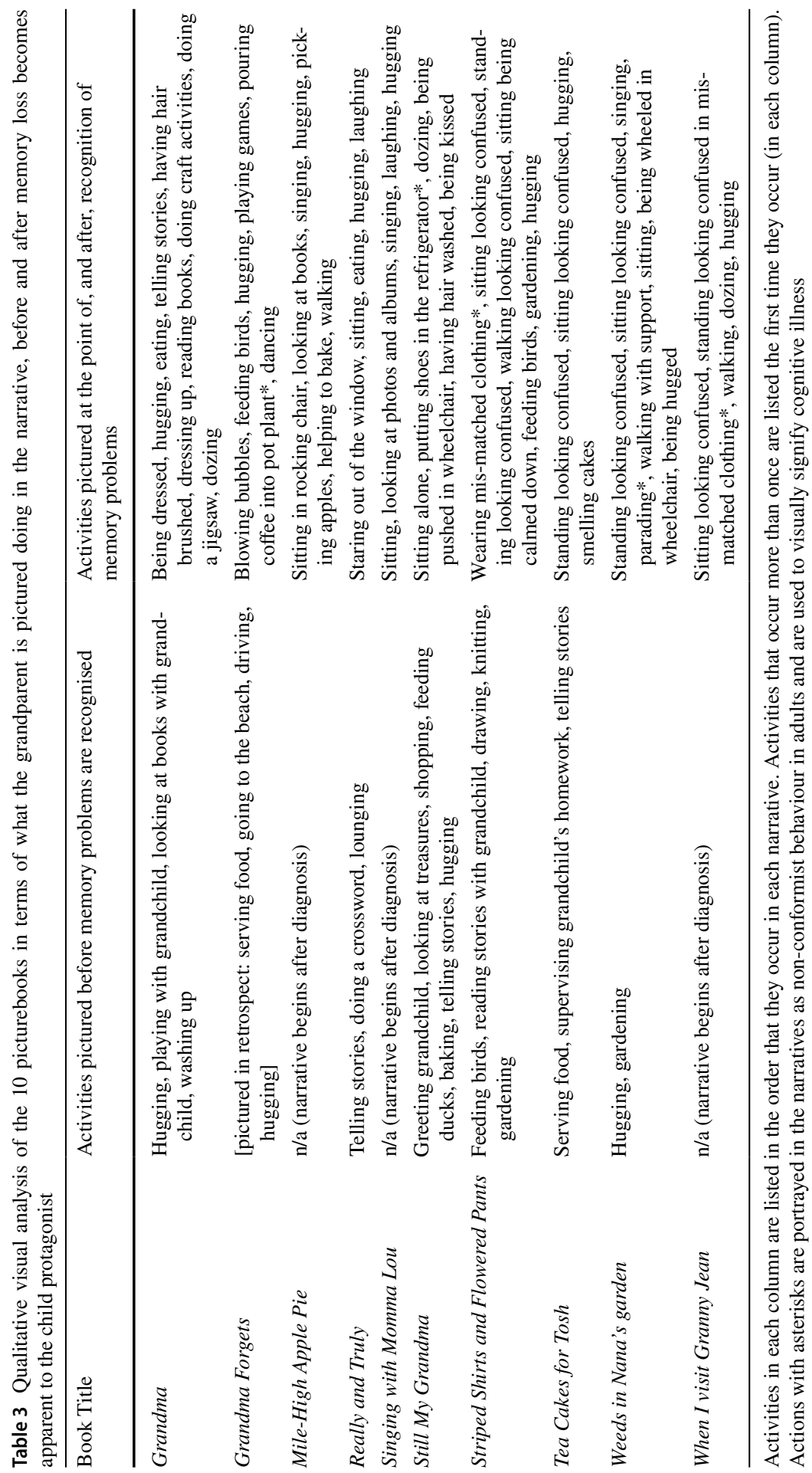


Because words and pictures communicate different kinds of relationships in different ways, the doubleness of picture books is not simply the repetition of the same information in a different form. The pictures inevitably convey a different story from the words. As a result, any given picture book contains at least three stories: the one told by the words, the one implied by the pictures, and the one that results from the combination of the first two. (1991, p. 2)

Pictures and words do not only complement and reinforce each other; they may also offer contradicting points of view (Nikolajeva and Scott, 2000). In some cases the pictures may convey more emotional content than is possible through the words alone (Nikolajeva, 2012), or may subvert the narrative carried through language by representing the child's point of view (Grenby, 2014). It is through a careful reading of image, word and image-word assemblages that we reveal the range of representations of illness that picturebooks about dementia present to young readers.

In order to focus specifically on the health communication in the picturebooks, we used a critical discourse analysis (Fairclough, 2015) approach to interrogate the health informational content about dementia and/or memory loss in the picturebooks. This involved examining the images, text and the peritexts for details of symptoms, descriptions and metaphors used to explain the cause of memory loss or a named dementia, as well as references to treatment and prognosis. In short, all images and text from the front to back cover of all 10 books were considered worthy of analysis. This is in contrast to the approach taken by Sakai et al. (2012), who deemed only the words to have medically relevant content in the storybooks they analysed. Furthermore, we included the peritext in our analysis, as although it was sometimes labelled as being intended for adult readers, such as in "Notes to Parents", we consider that it may also be accessible to children in the upper end of the age range to which many of the books are marketed (see Table 1). Furthermore, in some books the peritext was clearly directed at children and as such may provide a lens through which to read the rest of the book (Saunders, 2018).

In the sections that follow, we present our analysis in three parts, outlining the dominant aspects of health education about dementia in these books. The first section examines the association between dementia and ageing in the picturebooks. Following this, we explore the relationship between the mechanistic depiction of illness and a holistic conception of ongoing personhood in dementia. Finally, we discuss the treatment of prognosis and death in the picturebooks.

\section{Dementia and Ageing}

The abstract nature of cognition and memory presents challenges to illustrators of books for young children, and visual portrayals of dementia rely heavily on metaphorical and metonymic representations that themselves are dependent upon the broader cultural discourses of dementia. The most obvious challenge to producing a visual portrayal of dementia is that there are few outward physical signs of the condition, particularly in the early stages. It is not surprising, therefore, that only two of the picturebooks in our sample utilised specific graphic devices to signify 
cognitive difficulties and that they drew on common understandings of the symptoms of dementia to do so. Maltman and Devlin's When I Visit Granny Jean (2011) uses empty thought bubbles to symbolise Granny Jean's forgetfulness and loss of language. In Tea Cakes for Tosh (2012), by Lyons and Lewis, a pale blue wash descends progressively from the top of each page, which becomes a mist that gradually develops through the narrative. Eventually the blue mist covers Grandma Honey's head, just at the point in the story where her difficulty remembering everyday details becomes obvious to the child protagonist. The empty thought bubbles and the blue wash echo the common descriptions of the forgetting and confusion associated with dementia as a mist, blankness or darkness (see, for example, Zeilig, 2013 and Zimmerman, 2017 on images of darkness and light in dementia). Furthermore, these images are similar to those found in other fictional and non-fictional descriptions of the experience of dementia, where it is described as a sense of loss of place in the world (see, for example, DeBaggio's memoirs Losing My Mind: An Intimate Look at Life with Alzheimer's (2002) and When It Gets Dark: An Enlightened Reflection on Life with Alzheimer's (2003) and Genova's (2009) novel Still Alice).

The difficulty in representing cognitive illness in ways accessible to children may explain, at least in part, the alignment of ageing and dementia in these books. In our sample, all of the characters living with dementia are depicted in older age and are grandparents to the child protagonist. All but one of the books employ well established visual cultural markers of age (see Crawford and Bhattacharya, 2014) for the grandparent characters, such as grey hair, wrinkled skin and spectacles (see Table 2). ${ }^{1}$ The images in these books give a very clear message that dementia is something that happens to older people. Whilst the overwhelming emphasis on older adults as those with dementia in these books to some extent reflects the statistics, as 95\% of those diagnosed are over 65 (Prince et al., 2014), it is clear that the books both draw on and contribute to the close cultural association of dementia and ageing. This link between dementia and old age has led to what Higgs and Gilleard call the "Alzheimerisation of ageing," where cognitive health becomes the marker of successful old age and dementia represents society's dread about ageing itself (2017, p. 176). The close association of dementia and ageing in cultural narratives has other effects, too. Pat Sikes and Mel Hall, for example, argue that the dominant stereotype of dementia as a condition of old age is not only inaccurate but also unhelpful to children and young people who have a parent living with an early-onset dementia (Sikes and Hall, 2018). ${ }^{2}$

\footnotetext{
1 Only one of the books we examined did not use age markers in the drawing of the grandparent living with dementia. In Grandma (2014) by Jessica Shepherd, the grandmother has the same colour and texture of hair as the grandchild and other members of the family (creating a strong visual familial link) and does not have wrinkles or spectacles (see Fig. 4). In a conference workshop we ran looking at visual metaphors in in these books, when given an image of the character with dementia being helped with dressing without the text to anchor it, some participants interpreted her as a child, indicating the possibility of infantilisation. Nevertheless, the illustrations in the book are an example of the way that book producers can go beyond the more common visual representations of grandparents, and particularly those living with dementia, as people who have grey hair and wrinkles.

2 Early-onset dementia, where the condition affects someone who is under the age of 65, is also known as 'young-onset dementia'. In 2014, Prince et al (2014, p.17) reported that an estimated 42,325 people in
} 
The representation of the symptoms of dementia in these books also draws upon stereotypical ideas about, and figures of, ageing. In our sample, the most common visual device used to suggest difficulties with cognition is to illustrate unusual behaviour or dress (see Table 3). Capstick (2018) argues that nonconformist behaviour is one of the dominant cultural narratives of dementia; for example, adverts for Alzheimer's Disease medication have used images of an older woman pulling a flower apart, wearing one slipper and one shoe. By depicting unusual behaviour in grandparents, picturebooks turn such nonconformist behaviour into a signifier of cognitive illness. For example, in Still My Grandma (2006) by Van den Abele and Dubois, Grandma is pictured putting shoes in the refrigerator. Similarly, in Grandma Forgets (2017) by Russell and Johnston, Grandma is watering a house plant with coffee. In both of these examples, the non-conformity in behaviour immediately signals to a child that all is not as it should be. Even when the image is light-hearted and even comical, it also clearly indicates inability and confusion. For example, as Grandma pours her coffee into the plant in Grandma Forgets, the accompanying text is about her forgetfulness, and part of a narrative of dementia that emphasises the changes in Grandma. In these texts, then, the lack of adherence to behavioural norms in an older person is situated within (and provides support for) a narrative of illness.

In some children's literature, non-conformity may be a form of freedom that unites child and older adults (Joosen, 2018; Falcus and Sako, 2019), and that is sometimes also the case in the picturebooks we analysed. However, in picturebooks about dementia this is complicated by the use of non-conformist behaviour and dress to signify cognitive illness. This is shown in one of the most well-known books about Alzheimer's disease, Striped Shirts and Flowered Pants (Schnurbush, 2007) by Barbara Schnurbush and Cary Pillo. The first inkling that there is something wrong with Nana is when her clothes do not match - she is pictured wearing a striped shirt, incorrectly buttoned up, and flowered trousers. The granddaughter reads this mis-matched clothing as a form of non-conformity that links her and her grandmother: “One day, Mom noticed that Nana's clothes didn't match. It didn't bother me. My favourite outfit is my blue striped shirt with my orange pants. Grownups always think it doesn't match either." As the story progresses and it becomes apparent that Nana has Alzheimer's Disease, the little girl comes to understand that whilst it may be appropriate for a child to wear mis-matched clothes, for an older adult it indicates cognitive illness. In their clear depiction of non-conformity, therefore, the books implicitly reinforce normative standards of behaviour (and appearance) for healthy adults.

One of the key characteristics of dementia is the progressive nature of the condition, and picturebooks again draw on associations with ageing in order to make this progression comprehensible. Significantly, despite the non-linear nature of the experience of dementia for many, the books rarely stray from a linear narrative, often in the form of a 'before and after' story of illness. Many of the picturebooks

Footnote 2 (continued)

the UK lived with the condition. Young Dementia UK (2019) suggests that this is approximately 5\% of people living with dementia in the UK, but that the figures may be an underestimation. 
Fig. 1 From Really and Truly by Émilie Rivard, illustrated by Anne-Claire Delisle, Owlkids Books@ 2012. Reprinted with permission

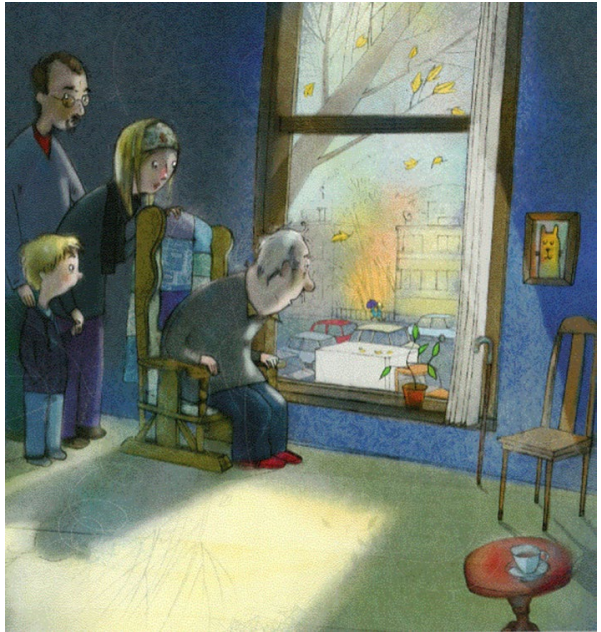

we examined indicate the progressive nature of illness through representations of changes to the physical body, arguably due to the challenges of representing cognitive and linguistic differences visually. Both Still My Grandma and Harrison's Weeds in Nana's Garden (2016) show the grandparent using walking aids after the point in the narrative where Alzheimer's Disease is diagnosed. There is also a notable change in the types of activities that the grandparent characters are pictured doing once the diagnosis of dementia occurs (see Table 3). Once it is apparent that the grandparents have memory problems, they are drawn as being more passive and sedentary than before and many are no longer shown carrying out caring roles, but rather are cared for by other adults or the child protagonist. As Salisbury and Styles stress, in picturebooks it is the sequential use of illustrations alongside minimal text that produces meaning (2012, p. 7; see also Moebius, 1986). Picturebooks are uniquely suited to the communication of the temporality and progression of illness narratives through their successive images and in these books that sequentiality is used to produce linear narratives of decline.

As well as progressive changes in mobility and activity types, the picturebooks illustrate the development of dementia through changes in facial expressions and bodily posture. Ageing and illness come together in these illustrations, as signifiers of ageing are conflated with signifiers of cognitive decline and aged bodies are represented as increasingly self-less and apart from others. In Still My Grandma, the previously smiling and tactile Grandma is pictured sitting slumped in her chair with a blank expression, just at the moment in the story when the child narrator becomes aware that her grandmother has "started acting different." The images of Grandma in the first part of the book emphasise activity (feeding the ducks, baking, shopping) and consistently depict Grandma and grandchild in close proximity. The image of grandma slumped in a chair shows her alone and not communicating with the child, who is far away on the opposite page of the double spread. The illustrations in subsequent pages largely represent Grandma as inactive and uncommunicative. Grandma's hair is less well-kept and in some images her wrinkles are emphasised. A 
Fig. 2 Cover of Russell and Johnston, Grandma Forgets. Reprinted by kind permission of Exisle Publishing

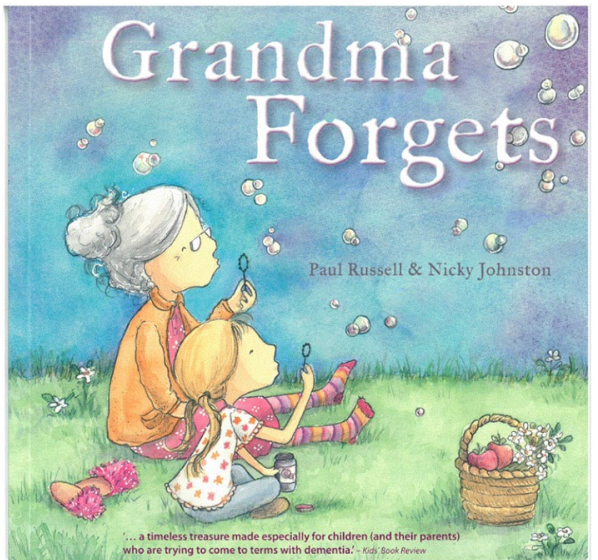

similar change in posture and facial expression is shown in the images of Grandpa in Rivard and Delisle's Really and Truly (2014), as the text describes the changing relationship between Charlie and Grandpa. The active and engaged grandpa becomes an aged, hunched figure who stares out of the window with his back to family members, who are separated from him by his gaze and his chair (see Fig. 1).

The decline and frailty frequently associated with old age makes progressive cognitive illness more comprehensible in these texts; at the same time it also distances it from youth. Several authors have suggested that a key concern for children is that they will develop dementia (see Manthorpe, 2005 for a review). The "Notes for Parents," included in several of the books, emphasise that children should be reassured that dementia is a condition that only occurs in adults. As such, the close association between dementia and older age in these books may distance children from the condition, and so allay children's fears about their own susceptibility. However, as Falcus and Sako (2019) point out, many books for children about dementia also simultaneously emphasise similarities between the child and grandparent. Examples of this include both characters wearing mis-matched clothing in Striped Shirts and Flowered Pants (discussed above), drawing on the close connection between childhood and older age that is a common feature of children's literature (as explored in many recent studies of intergenerational relationships in children's literature: see, for example, Joosen, 2018; Deszcz-Tryhubczak, 2018). Depictions of shared activities similarly function to bring together the two generations and are found in all the books we sampled, exemplified by the colourful and optimistic image of grandmother and child blowing bubbles together on the cover of Grandma Forgets (Fig. 2). The books therefore draw on the association between childhood and old age in order to engender in children greater identification with, and compassion for, people with dementia, at the same time as they distance the grandparent as an aged figure (in the process separating the child from the threat of illness). 


\section{Understanding Dementia}

The picturebooks' explanations for cognitive illness depend upon a mechanistic understanding of the body. In our sample there was a strong emphasis, in both the text and peritext, on the brain as the part of the body that is no longer functioning correctly and is causing memory problems. These explanations of illness are firmly rooted in the metaphor of the body as a machine and illness as caused by the incorrect functioning of particular parts (see Lupton, 2003 for a review of the mechanical metaphor). In Langston and Gardiner's Mile-High Apple Pie (2004) the mother tells the little girl that "Grandma's brain is all mixed up" and in Striped Shirts and Flowered Pants, the father explains that Nana's brain "wasn't working right." In When I Visit Granny Jean, the mother's explanation to the child of her grandmother's illness makes the machine metaphor explicit: "she said that sometimes when we get older we sort of run out of energy like when the batteries stopped in my remote-controlled dinosaur." This body-as-machine metaphor is found throughout western popular culture (Lupton, 2003) and is prevalent in children's books about the human body, such as the well-known illustrations of the different body machines by King in How Your Body Works (Hindley and King 1975). However, the machine metaphor has been widely critiqued as engendering too little recognition of the psychological, social and cultural aspects of health and illness (Martin 1992, Haraway, 1989).

The mechanistic metaphor is an integral part of the "reduction of memory (and mind) to brain function" (Katz, 2012, p.8) and the consequent medicalisation of dementia as brain pathology (a process that took place in the second half of the twentieth century, see Lock, 2013). This localisation of memory problems and other dementia symptoms in faulty brains has the clear benefit of offering a potential target for future treatments. As such, given the orientation of narratives for children towards happy endings and positive outlooks (see Tucker, 2006), it is perhaps not surprising that explanations of dementia for young children rely heavily on the bodyas-machine metaphor with its inherent optimistic implication that one day perhaps these problems can be fixed. Nevertheless, the biomedical and mechanistic understanding of dementia simply in terms of brain functioning has broader cultural consequences. Behuniak explains that the effects of the biomedical model enable, and are augmented by, cultural metaphors used in discourses of dementia, such as the disappearing person, to produce a "notion of the patient with Alzheimer's Disease as a non-person" (2011, p. 74). For Behuniak, this can result in a situation where someone with Alzheimer's Disease "no longer exists as a person but only as a body to be managed" (2011, p. 74). That sense of the disappearing person is implied in the images of mist and darkness, and in some of the depictions of physical frailty and isolation already noted in these picturebooks.

Some of the images in these books combine a mechanistic narrative of dementia with an implied loss of personhood and identity due to the reduction in cognitive function. Nevertheless, they complicate the reductive loss-of-self narrative by also suggesting the affective impact of loss of memory and associated loss of familial and broader social roles. As such, these books combine a biomedical with a more holistic understanding of health and illness. One such example is shown on a 
Fig. 3 Harrison, Weeds in Nana's Garden. Reprinted by kind permission of author

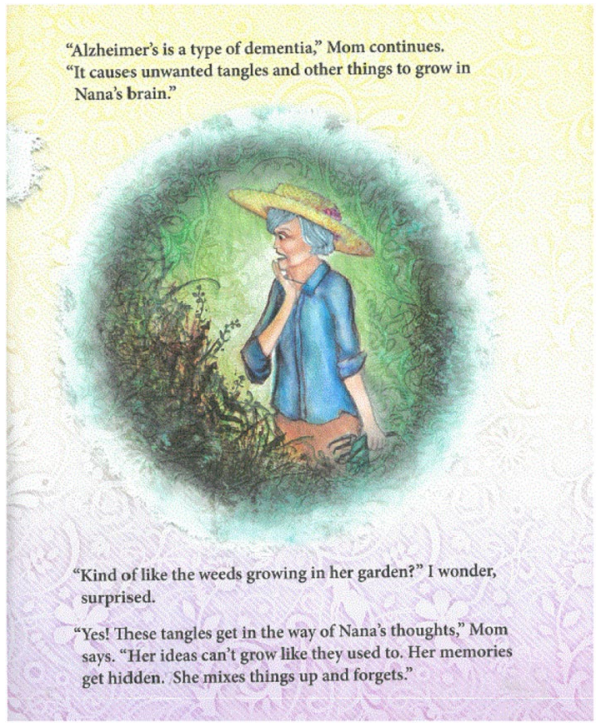

double-page spread from When I Visit Granny Jean. Here, Granny is pictured walking through the grounds of the nursing home. In the sky above her floats a piece of half-finished crochet that disintegrates into misty clouds that surround her head, reminiscent of the blue mist that engulfs Honey in Tea Cakes for Tosh mentioned earlier. The hedge that runs alongside her features mysterious forms in the topiary, but the text helps us to decode them and explains that she can no longer "train dogs, be a doctor or cook fairy cakes." The mention of Granny Jean's professional identity as a doctor is unusual as children's picturebooks rarely portray grandparents, and particularly grandmothers, as having an identity outside of the family (see Crawford and Bhattacharya, 2014). However, here the salient point is the loss of both this professional identity and her familial role as a "good" grandmother who bakes cakes. This example demonstrates the way in which the interplay of words and image hints at some of the profound sense of loss in terms of identity and personhood that cognitive illness can bring to both the person experiencing it and those around him/her.

Harrison's Weeds in Nana's Garden further explores the emotional and psychological effects of dementia for the person experiencing it. As with other texts, it draws on a mechanistic understanding of dementia as disease, using weeds to symbolise the biomedically-inspired depiction of dementia as tangles in the brain. The story centres on a young girl and her grandmother who are united by the pastime of gardening. The first inkling of something wrong comes as the girl notices more weeds than usual in the garden and the mother explains that Nana has Alzheimer's Disease. The image and text on the following page then develop the explanation of the biology of Alzheimer's into a metaphor of the weeds in the garden as like the neural tangles growing in the grandmother's brain. Plants and roots are common metaphors for dementia, where they represent the tangles associated with the neurological effects of dementia (see Zeilig, 2013 on tree imagery and dementia). Interestingly, the text only focuses on the cognitive effects of the tangles: "'Her ideas can't 
grow like they used to. Her memories get hidden. She mixes things up and forgets."” However, the image on the page also clearly shows an emotional effect of the disease in the fear and anxiety on the grandmother's face as she is encircled by the tangle of weeds that threaten to engulf her (see Fig. 3). Without the text, the metaphorical meaning of the weeds would be lost, but without the image we would have only a very matter-of-fact description of the cognitive effects of the condition, without the depiction of the strong emotions that can accompany the cognitive symptoms. Similarly, McNicol's (2016) study of health educational comics showed that participants found images more powerful than words for conveying complex emotional states and some found the images in particular to be disturbing and distressing. Images in picturebooks therefore circumvent the need to describe emotions with words and in this case they supplement the basic, mechanistic textual explanation with a more complex, and arguably more adult (Nodelman, 2010), depiction of psychological distress.

Another aspect of the holistic conception of health found in these books is their reliance on the "still the same person" narrative. This concept was developed in the care professions and in dementia activism to engender recognition for the identities and histories of people living with dementia (see Sikes and Hall, 2018). The titles of some books make this message explicit, as in Still My Grandma. In others, the words emphasise ongoing personhood through intergenerational security, as seen in the final lines of Shepherd's Grandma (2014): "She is still the best Grandma in the whole wide world." These narratives defy the physical and behavioural changes wrought by cognitive illness and emphasise the ongoing identity of, and potential for relationships with, people living with dementia.

Emphasising the persistence of identity in dementia, many of the picturebooks' storylines are based upon the maintenance of selfhood through activities that preserve memory and with it a story of self, such as the memory box in Grandma, and the scrapbook in Altman and Johnson's Singing with Momma Lou (2002). The picturebooks use this narrative to offer reassurance to a child reader, and perhaps also to the adult reader/book purchaser, that the relationship with a loved one - and the shared history that is part of that - will not be lost. And indeed in these narratives it is usually the child who is able to support the ongoing sense of identity in the grandparent with dementia (see Falcus and Sako, 2019). For example, Tosh takes his grandmother teacakes and reminds her of family stories in Tea Cakes for Tosh. Similarly, Mile-High Apple Pie is an example of the many narratives that depict the child as the holder of memory, as the grandchild sits on her grandmother's lap and asserts that "I am your remembering." This accords with Joosen's argument that children's literature (more broadly) is not straightforwardly ageist and may offer potentially empowering visions of older people. Joosen suggests that though depictions of older people may indicate their lack of power and be limited in range, there are ways in which older adults are empowered, especially through relationships with children (2015, p. 138). Picturebooks about dementia demonstrate this dialogism; they are complex texts which employ often ageist tropes of decline in the depiction of dementia and yet at the same time support a narrative of ongoing personhood.

The "still the same person" narrative itself is not entirely straightforward either. Whilst it has undoubtedly helped to increase awareness of the need for compassion 
Fig. 4 Shepherd, Grandma.

Reproduced by kind permission of Child's Play (International) Ltd. Grandma ( ) Jessica Shepherd. First published 2014 by Child's Play. All rights reserved

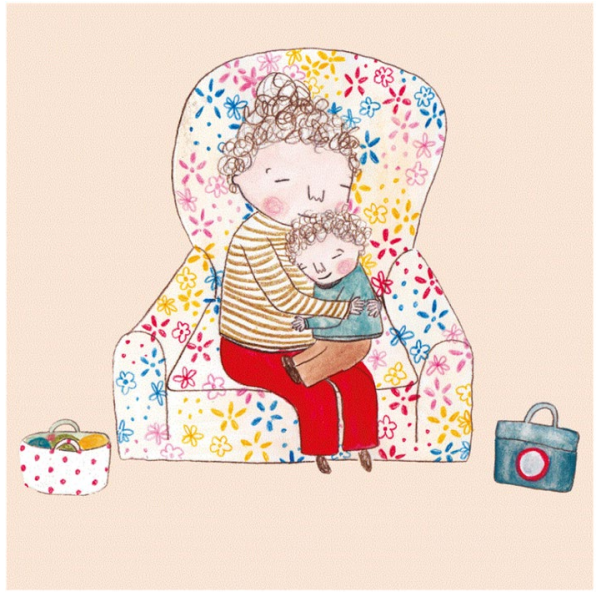

among carers, it has inherent contradictions. To the young people in Sikes and Hall's (2018) study, the suggestion that their parent living with dementia was still the same person as they had been prior to their diagnosis was often unhelpful and even offensive. In the picturebooks, there is a clear tension between the text and peritexts that emphasise the "still the same person" narrative, and the images which more clearly show the contrast between the grandparent before and after the onset of dementia. As Grenby points out, the text in picturebooks "generally conveys the educational and 'literary' content," or the "'official' account," whereas the pictures represent the child's point of view (2014, pp. 217-218). In these picturebooks, the child protagonists (and readers) can see that the grandparent looks different at the end of the book as compared to the beginning, but the educational message is to move beyond these appearances to an understanding of the grandparent that includes both memories of happier times and the grandparent's own history.

\section{Prognosis, Death and Endings}

One aspect that is conspicuously absent from these picturebooks is the specific indication that the progressive nature of dementias may eventually result in the grandparent's death. This aligns with other research into illness in children's books; for example, Blumenreich and Siegel's (2006) analysis of children's books about HIV/ AIDS also found that death was mentioned infrequently. On closer inspection of the dementia picturebooks, there are a number of other possible explanations for death not being featured. Firstly, the express intention of all of these picturebooks is to reassure children in the face of the confusing changes in their family. For example, in Striped Shirts and Flowered Pants, the granddaughter is worried that her grandmother might die. But then the reader is explicitly reassured both by the image of the parents comforting the child in bed and by the accompanying text: "Daddy said that Nana would live a long time." Secondly, an important aim of the books is to enable children to maintain a relationship with a grandparent whilst he or she is still 
living. As Falcus and Sako (2019) point out, a hug between grandchild and grandparent is a common ending to this kind of picturebook (see, for example, the image from Grandma, Fig. 4) and it is clear from this treatment that the intention is to reassure and comfort children as they experience the changes in their grandparent and their families, rather than to dwell on the pessimism of the prognosis.

Aspects of the genre itself also preclude the likelihood of the narratives ending on a negative note. Natov suggests that "a poetics for children requires a delicate rendering of hope and honesty" (2002, p. 220) and so happy endings are common and depressive endings are traditionally shunned in stories for children (Tucker, 2006). Tellingly, all of the children's books about depression in Imogen Church's (2016) study ended with some kind of resolution, if not a cure then an acceptance, reduction or management of the condition. Whilst there is arguably less scope for this in dementia, the "still my grandparent" narrative discussed above allows the books to end on a positive note. In this way, the picturebooks can be viewed in the context of the family story, one of the most common genres in children's literature and one which charts a disruption to happy family life, followed by a focus on the reconstruction or reconstitution of an adapted family (see Tucker and Gamble, 2001). In the picturebooks, dementia brings about changes to both the grandparent and family life and the narratives chart the way both the family and child adapt, cope and come to terms with the effects of the condition. As the peritexts in Grandma explain, "People can still live well with dementia," and it is clear that the narratives intend to help children play their part in this.

In contrast to all of the other books we examined, When I Visit Granny Jean does mention the eventual death of the grandparent. However, this information is given to us in the context of ageing, and not as a result of the specific process of dementia. This construction of death as a consequence of old age is a common explanation that is given to children, and as Wiseman (2013, p. 3) points out, children "often attribute death as something that happens only to those who are old and frail." It could also be argued that as dementia is frequently framed as concurrent with old age, it circumvents the need to explain to children that, as dementia is progressive and there is currently no cure, their grandparents will eventually die rather than get better.

Two other picturebooks in our sample do obliquely hint at the possibility of the grandparent's death. The final double-page spread of Weeds in Nana's Garden shows the granddaughter on her own in the grandmother's garden, but it is not made clear whether Nana has moved to residential care or has died. The garden here has a memorial function as the granddaughter continues to tend and enjoy it even without her grandmother (see Wiseman, 2013). Similarly, in Singing with Momma Lou, at the end of the book Tamika is pictured alone with the scrapbook she had made of Momma Lou's life, surrounded by sepia figures from the days of Momma Lou's civil rights activism. The preceding page states that "Momma Lou's eyes went empty and stayed that way. It was sad of course and Tamika cried. But mostly she remembered." Although we are not explicitly told that Momma Lou has died, we can infer that this is a possibility. This ambiguity is a common feature of books for young children, which can have a number of readings depending on the age and experience of the reader. As Reynolds (2011, p. 126) points out: "As a rule, books for children and young adults tend to be vague when referring to potentially disturbing acts or 
events; readers may fill in the gaps and add details as far as they can or want to." Notably, books about dementia aimed at older children are less likely to shy away from the death of a grandparent.

\section{Conclusion}

In her analysis of cultural stories about dementia, Zeilig argues that metaphors about dementia are important as they "become subconsciously ingested and inform how we feel about dementia and how we interact with people with dementia" (2013, p. 265). The metaphors, images and stories in picturebooks about dementia are significant because they have the potential to shape the ideas and behaviours of the next generation. The books in our sample all have express intentions to help children understand and cope with the changes that dementia brings to family life and to support the maintenance of relationships between children and older adults living with the condition. From our analysis, it is clear the books align with some of the key themes in contemporary dementia awareness movements, such as emphasising the "still the same person" narrative and the importance of ongoing connection with someone despite dementia. However, our study also reveals a number of aspects which make these picturebooks less than straightforward texts for health communication. Relying on the close association between ageing and dementia, and drawing on mechanistic metaphors to explain the condition, the books sometimes contribute to the loss-of-self discourse of dementia. At the same time, they do engage with the social, affective and psychological effects of dementia, reflecting a more holistic understanding of ill health. There is then sometimes a tension between different models of health in depictions of dementia in these books, which is perhaps an inevitable result of trying to summarise concepts such as cognitive illness in very few words for young children, but also reflects wider competing discourses of dementia. As this study has shown, metaphors and depictions of cognitive illness require both attending to and interrogating in order to establish the effects that they can have on children's understanding and views of dementia. We would argue that a greater awareness of the role of metaphor in shaping ideas about health is needed so that educators and authors have a wider range of devices to draw on when writing for young children about illness. Whilst the current analysis is theoretical in nature, gathering the responses to our sample of picturebooks from children, parents and people living with dementia is an obvious next step for future research.

Open Access This article is licensed under a Creative Commons Attribution 4.0 International License, which permits use, sharing, adaptation, distribution and reproduction in any medium or format, as long as you give appropriate credit to the original author(s) and the source, provide a link to the Creative Commons licence, and indicate if changes were made. The images or other third party material in this article are included in the article's Creative Commons licence, unless indicated otherwise in a credit line to the material. If material is not included in the article's Creative Commons licence and your intended use is not permitted by statutory regulation or exceeds the permitted use, you will need to obtain permission directly from the copyright holder. To view a copy of this licence, visit http://creativecommons.org/licen ses/by/4.0/. 


\section{References}

Altman, Linda Jacobs, and Johnson, Larry. (2002). Singing with Momma Lou. New York: Lee \& Low Books.

Alzheimer's Association. (2017). Alzheimer's Association Report: 2017 Alzheimer's Disease Facts and Figures. Alzheimer's \& Dementia, 13, 325-373.

Bartlett, Ruth, Gjernes, Trude, Lotherington, Ann-Therese, and Obstefelder, Aud. (2018). Gender, Citizenship and Dementia Care: A Scoping Review of Studies to Inform Policy and Future Research. Health and Social Care in the Community, 26(1), 14-26.

Beauvais, Clémentine. (2015). The Mighty Child: Time and Power in Children's Literature. Amsterdam: John Benjamins Publishing.

Behuniak, Susan M. (2011). The Living Dead? The Construction of People with Alzheimer's Disease as Zombies. Ageing and Society, 31(1), 70-92.

Blumenreich, Megan, and Siegel, Marjorie. (2006). Innocent Victims, Fighter Cells, and White Uncles: A Discourse Analysis of Children's Books about AIDS. Children's Literature in Education, 37(1), 81-110.

BookTrust (2019). Books on Dementia. Accessed Jan 14, 2020 from https://www.booktrust.org.uk/book1 ists/c/childrens-books-on-dementia/.

Caldwell, Elizabeth F., and Wilbraham, Susan J. (2018). Hairdressing in Space: Depiction of Gender in Science Books for Children. Journal of Science and Popular Culture, 1(2), 101-118.

Capstick, Andrea. (2018). Dementia and Cultural Narrative: Four Dimensions. In: Working Together: Collaboration Beyond the Academy in Research in Dementia and Culture. 23rd November, 2018. London: Institute of Modern Languages Research, University of London.

Centre for Literacy in Primary Education. (2018). Reflecting Realities: Ethnic Diversity in UK Children's Books. Retrieved January 20, 2019, from https://clpe.org.uk/library-and-resources/research/refle cting-realities-survey-ethnic-representation-within-uk-children.

Christiansen, Pia. (2004). The Health-Promoting Family: A Conceptual Framework for Future Research. Social Science \& Medicine, 59(2), 377-387.

Crawford, Patricia A., and Bhattacharya, Sharika. (2014). Grand Images: Exploring Images of Grandparents in Picture Books. Journal of Research in Childhood Education, 28(1), 128-144.

Church, Imogen. (2016). The Picture of Madness - Visual Narratives of Female Mental Illness in Contemporary Children's Literature. Children's Literature in Education, 49(2), 119-139.

DeBaggio, Thomas. (2002). Losing My Mind: An Intimate Look at Life with Alzheimer's. New York: Free Press.

DeBaggio, Thomas. (2003). When It Gets Dark: An Enlightened Reflection on Life with Alzheimer's. New York: Free Press.

Deszcz-Tryhubczak, Justyna. (2018). An Intergenerational Approach to Representations of Childhood and Adulthood in Children's Literature. Literature Ludowa, 3. Accessed Jan 14, 2020 from http:// apcz.umk.pl/czasopisma/index.php/LL/article/view/18761/16244.

Downham, Jenny. (2015). Unbecoming. Oxford: David Fickling Books.

Elliott, Matt, and Nunn, David William. (2015). When Grandma Came to Stay. London: Alzheimer's Research UK.

Elliott, Matt, and Threadgold, James M. (2015). Grandad's Hat. London: Alzheimer's Research UK.

Fairclough, Norman. (2015). Language and Power, 3rd ed. Abingdon: Routledge.

Falcus, Sarah, and Sako, Katsura. (2019). Contemporary Narratives of Dementia: Ethics, Ageing, Politics. New York: Routledge.

Furniss, Claire. (2016). How Not to Disappear. London: Simon and Schuster.

Genova, Lisa. (2009/2007). Still Alice. London: Pocket Books.

Grenby, Matthew O. (2014). Children's Literature, 2nd ed. Edinburgh: Edinburgh University Press.

Gubar, Marah. (2013). Risky Business: Talking about Children in Children's Literature Criticism. Children's Literature Association Quarterly, 38(4), 450-457.

Haraway, Donna. (1989). The Biopolitics of Postmodern Bodies: Determinations of Self in Immune System Discourse. Differences: A Journal of Feminist Cultural Studies, 1(1), 3-43.

Harrison, Kathryn. (2016). Weeds in Nana's Garden: A Heartfelt Story of Love That Helps Explain Alzheimer's Disease and Other Dementias. Cobourg: Flipturn Publishing.

Higgs, Paul, and Gilleard, Chris. (2017). Ageing, Dementia and the Social Mind: Past, Present and Future Perspectives. Sociology of Health and Illness, 39(2), 175-181. 
Hindley, Judy, and King, Colin. (1975). How Your Body Works: A trip around the body machine. London: Usborne.

Joosen, Vanessa. (2015). Second Childhoods and Intergenerational Dialogues: How Children's Literature Studies and Age Studies Can Supplement Each Other. Children's Literature Association Quarterly, 40(2), 126-140.

Joosen, Vanessa (Ed.). (2018). Connecting Childhood and Old Age in Popular Media. Jackson, Mississippi: University Press of Mississippi.

Katz, Stephen. (2012). Embodied Memory: Aging, Neuroculture, and the Genealogy of Mind. Occasion: Interdisciplinary Studies in the Humanities, 4. Retrieved March 3, 2013, from https://arcade.stanf ord.edu/sites/default/files/article_pdfs/OCCASION_v04_Katz_053112_0.pdf.

Langston, Laura, and Gardiner, Lindsey. (2004). Mile-High Apple Pie. London: Bodley Head.

Lock, Margaret. (2013). The Alzheimer Conundrum: Entanglements of Dementia and Aging. Princeton, NJ: Princeton University Press.

Lupton, Deborah. (2003). Medicine as Culture: Illness, Disease and the Body in Western Societies, 2nd ed. London: Sage.

Lyons, Kelly Starling, and Lewis, E.B. (2012). Tea Cakes for Tosh. New York: G.P.Putnam's Sons.

Maltman, Elizabeth, and Devlin, Amy. (2011). When I Visit Granny Jean. Cambridge: Pegasus.

Manthorpe, Jill. (2005). A Child's Eye View: Dementia in Children's Literature. British Journal of Social Work, 35, 305-320.

Martin, Emily. (1992). The Woman in the Body: A Cultural Analysis of Reproduction, 2nd ed. Boston, MA: Beacon Press.

McNicol, Sarah. (2016). The Potential of Education Comics as a Health Information Medium. Health Information and Libraries Journal, 31(1), 20-31.

Mielke, Michelle M. (2018). Sex and Gender Differences in Alzheimer's Disease Dementia. Psychiatr Times, 35(11), 14-17.

Miller-Ott, Aimee E. (2018). "Just a heads up, my father has Alzheimer's:" Changes in Communication and Identity of Adult Children of Parents with Alzheimer's Disease. Health Communication, https:// doi.org/10.1080/10410236.2018.1547676.

Moebius, William. (1986). Introduction to Picturebook Codes. Word \& Image, 2(2), 141-158.

Natov, Roni. (2002). The Poetics of Childhood. London: Routledge.

Nikolajeva, Maria. (2012). Reading Other People's Minds through Word and Image. Children's Literature in Education, 43(3), 273-291.

Nikolajeva, Maria, and Scott, Carole. (2000). The Dynamics of Picturebook Communication. Children's Literature in Education, 31(4), 225-239.

Noble, James M., Hedman, Monique G., and Williams, Olajide. (2015). Improving Dementia Health Literacy Using the FLOW Mnemonic: Pilot Findings from the Old SCHOOL Hip-Hop Programme. Health Education and Behaviour, 42(1), 73-83.

Nodelman, Perry. (1991). The Eye and the I: Identification and First-Person Narratives in Picture Books. Children's Literature, 19, 1-30.

Nodelman, Perry. (2010). Words Claimed: Picturebook Narratives and the Project of Children's Literature. In Teresa Colomer, Bettina Kümmerling-Meibauer and Cecilia Silva-Díaz (Eds.), New Directions in Picturebook Research (pp. 11-26). New York: Routledge.

Park, Barbara. (2002). The Graduation of Jake Moon. New York: Aladdin Paperbacks.

Parveen, Saadia. (2015). Effect of dementia on young people. Care and Cure Magazine, Autumn 2015. Retrieved May 2, 2019, from https://www.alzheimers.org.uk/research/care-and-cure-research-magaz ine/effect-dementia-young-people.

Prince, M., Knapp, M., Guerchet, M., McCrone, P., Prina, M., Comas-Herrera, A., Wittenberg, R., Adelaja, B., Hu, B., King, D., Rehill, A. and Salimkumar, D. (2014). Dementia UK: Update Second Edition report produced by King's College London and the London School of Economics for the Alzheimer's Society. Retrieved May 2, 2019, from http://eprints.1se.ac.uk/59437/1/Dementia_UK_Secon d_edition_-_Overview.pdf.

Reading Well (2020). Resources: Dementia. Accessed Jan 14, 2020 from https://reading-well.org.uk/ resources/dementia.

Reynolds, Kimberley. (2011). Children's Literature: A Very Short Introduction. Oxford: Oxford University Press.

Rivard, Émilie, and Delisle, Anne-Claire. (2014). Really and Truly: A Story about Dementia. London: Franklin Watts. 
Rocca, Walter A. (2017). Time, Sex, Gender, History, and Dementia. Alzheimer Disease and Associated Disorders, 31(1), 76-79.

Russell, Paul, and Johnston, Nicky. (2017). Grandma Forgets. Chatswood, Australia: EK Books.

Salisbury, Martin, and Styles, Morag. (2012). Children's Picturebooks: The Art of Visual Storytelling. London: Laurence King.

Sakai, Erin Y., Carpenter, Brian D., and Rieger, Rebecca E. (2012). "What's Wrong with Grandma?": Depictions of Alzheimer's Disease in Children's Storybooks. American Journal of Alzheimer's Disease and Other Dementias, 27(8), 584-591.

Sandberg, Linn J. (2018). Dementia and the Gender Trouble? Theorising Dementia, Gendered Subjectivity and Embodiment. Journal of Aging Studies, 45, 25-31.

Saunders, Joe Sutliff. (2018). A Literature of Questions: Nonfiction for the Critical Child. Minneapolis: University of Minnesota Press.

Schnurbush, Barbara, and Pillo, Cary. (2007). Striped Shirts and Flowered Pants: A Story about Alzheimer's Disease for Young Children. Washington, DC: Magination Press.

Shepherd, Jessica. (2014). Grandma. Swindon: Child's Play.

Sikes, Pat, and Hall, Mel. (2018). "It was then that I thought 'Whaat? This is not my Dad:" The Implications of the 'Still the Same Person' Narrative for Children and Young People who have a Parent with Dementia. Dementia, 17(2), 180-198.

Sipe, Lawrence R. (1998). How Picture Books Work: A Semiotically Framed Theory of Text-Picture Relationships. Children's Literature in Education, 29(2), 97-108.

Sipe, Lawrence R. (2011). The Art of the Picturebook. In S.A. Wolf, K. Coats, P. Encisco and C. Jenkins (Eds.), Handbook of Research in Children's and Young Adult Literature (pp. 238-252). New York: Routeledge.

Styles, Morag, and Arizpe, Evelyn. (2001). A Gorilla with "Grandpa's Eyes": How Children Interpret Visual Texts-A Case Study of Anthony Browne's Zoo. Children's Literature in Education, 32(4), 261-281.

Tucker, Nicholas. (2006). Depressive Stories for Children. Children's Literature in Education, 37(3), 199-210.

Tucker, Nicholas, and Gamble, Nikki. (2001). Family Fictions. London: Continuum.

Van den Abele, Véronique, and Dubois, Claude K. (2006). Still My Grandma. Grand Rapids, Michigan: Eerdmans.

Wiseman, Angela M. (2013). Summer's End and Sad Goodbyes: Children's Picturebooks About Death and Dying. Children's Literature in Education, 44(1), 1-14.

Young Dementia UK (2019). Young Onset Dementia Facts and Figures. Retrieved October 15, 2019, from: https://www.youngdementiauk.org/young-onset-dementia-facts-figures.

Zeilig, Hannah. (2013). Dementia as a Cultural Metaphor. The Gerontologist, 54(2), 258-267.

Zimmerman, Martina. (2017). Alzheimer's Disease Metaphors as Mirror and Lens to the Stigma of Dementia. Literature and Medicine, 35(1), 71-97.

Publisher's Note Springer Nature remains neutral with regard to jurisdictional claims in published maps and institutional affiliations.

\section{Affiliations}

\section{Elizabeth F. Caldwell ${ }^{1}\left[\right.$ Sarah Falcus $^{2}\left(\mathbb{D} \cdot\right.$ Katsura Sako $^{3}(\mathbb{C}$}

Elizabeth F. Caldwell

e.caldwell@lancaster.ac.uk

1 Lancaster University, Lancaster LA1 4YH, UK

2 University of Huddersfield, Queensgate, Huddersfield HD1 3DH, UK

3 Keio University, 4-1-1 Hiyoshi Kohoku-ku, Yokohama-shi Kanagawa 223-8521, Japan 